\title{
Perspectivas pedagógicas em Nietzsche: diálogo, agonismo e o cultivo de si
}

\author{
Lúcia Schneider Hardt \\ Universidade Federal de Santa Catarina (Brasil)
}

\section{Resumo}

Este estudo de caráter bibliográfico tem como propósito destacar o lugar e a importância do diálogo na obra de Nietzsche e conectála com a ideia de agonismo, também importante na obra do filósofo e desenvolvida por Acampora, para refletir sobre a importância dessa conexão para a educação. Tanto a disputa quanto o diálogo nas práticas educativas são procedimentos de enfrentamento da violência, produzindo valores, padrões de medida e sentidos para a convivência humana. A ideia do diálogo e de disputa solicitam uma ideia de cultivo de si desenvolvida por Nietzsche e que inaugura outra pedagogia, que nos coloca no lugar de quem é convidado a evitar a ossificação de uma perspectiva na forma de tirania e ativar em cada um seu processo de individualização, que em alguma medida é um antídoto à sedução ao rebanho para, então, inventar rotas de fuga, criando performances para um pensar e agir mais livres.

Palavras-chave: Diálogo. Nietzsche. Acampora. Cultivo de si.

\section{Pedagogical perspectives in Nietzsche: dialogue, agonism and the self-cultivation}

\section{Abstract}

This bibliographic study aims to highlight the place and importance of dialogue in Nietzsche's work and to connect it with the idea of agonism, also important in the philosopher's work developed by Acampora, to reflect on the importance of this connection for education. Both dispute and dialogue in educational practices are procedures for confronting violence, producing values, measurement standards and meanings for human coexistence. The idea of dialogue and dispute calls for an idea of self-cultivation developed by Nietzsche and that opens another pedagogy, which puts us in the place of those who are invited to avoid ossifying a perspective in the form of tyranny and activating in each one his individualization process, which to some extent is an antidote to seduction to the herd, then, inventing escape routes by creating performances for freer thinking and acting.

Keywords: Dialogue. Nietzsche. Acampora. Self-cultivation. 


\section{Perspectivas Pedagógicas en Nietzsche: diálogo, agonismo y cultivo de si}

\section{Resumen}

Este estudio bibliográfico tiene como objetivo resaltar el lugar y la importancia del diálogo en la obra de Nietzsche y conectarla con la idea del agonismo, también importante en la obra del filósofo y desarrollada por Acampora, para reflexionar sobre la importancia de esta conexión para la educación. Tanto la disputa como el diálogo en las prácticas educativas son procedimientos para enfrentar la violencia, producir valores, estándares de medición y sentidos para la convivencia humana. La idea de diálogo y disputa requiere una idea de autocultivo desarrollada por Nietzsche y que inaugura otra pedagogía, que nos coloca en el lugar de aquellos que están invitados a evitar osificar una perspectiva en forma de tiranía y activar en cada un su proceso de individualización, que en cierta medida es un antídoto para la seducción del rebaño para, luego, inventar rutas de escape, creando acciones para un pensamiento y una actuación más libres.

Palabras clave: Diálogo. Nietzsche. Acampora. Autocultivo.

\section{Introdução e apresentação ao tema}

artigo tem como objetivo destacar o lugar e a importância do diálogo na obra de Nietzsche e conectá-la com a ideia de agonismo, também importante na obra do filósofo e desenvolvida por Acampora, para refletir sobre a importância dessa conexão para a educação. Tomar Nietzsche como parâmetro não significa negar outra tradição, mas estabelecer diálogos para problematizar essas outras abordagens sem perder a dimensão de que o critério de análise implica sempre uma perspectiva. $\bigcirc$ texto deseja aprofundar a dimensão do diálogo como forma filosófica em Nietzsche, visando a apreender a dimensão pedagógica presente em Nietzsche, inventar rotas de fuga, criando performances de orientação para um pensar e agir mais livres que, se possível, possam efetivar-se esteticamente, garantindo um tanto de beleza para a educação e o fazer pedagógico em nosso país.

Segundo Claus Zittel (2016), Nietzsche esboçou muitos diálogos e eles são muito perceptíveis nas obras A gaia ciência e Aurora. Eles operam como uma função filosófica e conectam-se com um estilo literário de exposição para solicitar a presença do leitor para pensar. Se o diálogo também é produzido por Nietzsche, por que ele combate outros tipos de diálogo expressos na 
Perspectivas pedagógicas em Nietzsche: diálogo, agonismo e o cultivo de si

tradição filosófica? Parece, como nos diz Zittel (2016), que é outro tipo de diálogo que Nietzsche quer destacar, outra conversação, a saber, conversação que não se baseia mais em poder e violência. Segundo Zittel, diferentemente do que se espera de Nietzsche, poucos diálogos agonais estão presentes em sua obra, nos quais o orador supera seu oponente com sua melhor eloquência, seu argumento ou poder. Talvez aqui fosse possível criar algumas dissonâncias sobre o termo agon, se tivéssemos como critério o texto de Acampora, especialmente seu livro As disputas de Nietzsche (2018).

A autora nos oferece um estudo interessante sobre a noção de agon (disputa) no conjunto da filosofia de Nietzsche. Segundo ela, o agon não seria violento, mas contribuiria tanto para a autossuperação quanto para sofisticar a vida em comunidade, produzindo valores, padrões de medida e sentidos para a vida. Tentaremos, neste texto, fazer essas conexões entre a defesa dos diálogos proposta por Zittel e a noção de disputa não violenta proposta por Acampora. Segundo Zittel',

[...] os diálogos de Nietzsche não seguem na maioria das vezes os padrões clássicos, mas os contrariam. Pois não se trata neles nem da disseminação do saber nem da mediação do poder - como no Diálogo dos Meliano -, e também não da disputa pública na tribuna. Neles são testados, ao invés disso, formas de conversação íntimas e enigmáticas que não acabam trocando posições, mensagens e verdades, mas antes em uma maneira cortês, inteligente e suave de se relacionar com outra pessoa, por meio de um modo de se comunicar estético. Na maioria dos diálogos de Nietzsche não predominam, desse modo, o triunfar, o destruir, o defender o próprio direito, "a disputa odiosa" (Nachlass, 1876, 16[46], KSA 8.2941, mas em sua maioria a prudência e o respeito, o desembaraço e a gentileza do melhor argumento poupado ou detido, a renúncia à refutação, o reconhecimento de outras posições, bem como um querer não-ser-entendido e um não-ter de-entender (ZITTEL, 2016 , p. 4).

Segundo Acampora ${ }^{2}$,

A disputa agonística, especula Nietzsche, é uma força produtiva que regula, sem subjugar, os interesses dos indivíduos, coordenando-se sem reduzi-los aos interesses da comunidade e providenciando uma abertura radical para a circulação de poder que evita sua ossificação na forma de tirania. Ela também disponibiliza 
um meio para a produção de indivíduos ao permitir que os participantes se distingam uns dos outros, através de seus feitos, dentro de interações competitivas. Desta maneira, relações agonísticas criam um contexto que faz emergir performances distintas; entendidas desta forma, elas literalmente ativam o processo de individualização, o fundamento segundo o qual nos distinguimos uns dos outros. Além disso, o agon também produz comunidades na medida em que gera significância social através de relações entre indivíduos e a comunidade de juízes que testemunham e sancionam a ação produzida na troca agonística (ACAMPORA, 2018, p. 51 ).

A autora demonstra que Nietzsche admite os vários tipos de disputa que a tradição cultivou, mas, tal como Zittel - e essa é nossa tese - parece que destaca um fator positivo no modo agonístico, que não apenas prioriza seu adversário, competidor, mas deseja promover uma espécie de excelência que tem repercussões para a vida social também. Afinal, o que deseja Nietzsche com a disputa com o cristianismo? Ele pretende afirmar a vida, enfrentar a noção de pecado, má consciência, oferecer outro sentido de vida. Nossa defesa, ainda conectando esses dois autores, é defender a ideia de que a práxis da noção do cultivo de si inaugura outra pedagogia, pois nos coloca no lugar de quem é convidado a, primeiramente, dar atenção a um diálogo, a uma disputa para evitar a ossificação de uma ideia na forma de tirania e ativar em cada um seu processo de individualização, que em alguma medida é um antídoto à sedução ao rebanho.

Tomando o livro Aurora, aforismo 485 - perspectivas longínquas definido por Zittel como a expressão de um diálogo em Nietzsche, tentarei compor uma conexão coma noção de disputa sugerida por Acampora.

Indaga nosso filósofo, por meio de um interlocutor A:

"- Mas por que esta solidão?"

E o personagem B, responde:

"- Não estou aborrecido com ninguém. Contudo, quando sozinho parece que consigo ver tudo melhor. Meus amigos, a música que aprecio, longe outra luz parece fazer aparecer o que perto não enxergava." (Adaptação do diálogo). E o diálogo finaliza com a seguinte expressão: "[...] parece que eu necessito das perspectivas longínquas para pensar bem sobre as coisas" (NIETZSCHE, 2008, p. 230-231). 
Perspectivas pedagógicas em Nietzsche: diálogo, agonismo e o cultivo de si

Segundo Zittel, são vários os diálogos presentes na escrita de Nietzsche, e, por vezes, nem sempre valorizados na pesquisa sobre seu estilo e forma filosófica. Tomamos um, pode nem ser o mais adequado, mas desejamos estabelecer as conexões entre os dois autores citados para defender a tese do cultivo de si também por meio do diálogo e da disputa que providenciariam outra pedagogia.

Perspectivas longínquas implicam um distanciamento, sugerem que outra luz fica materializada para poder, por um tempo, contemplar o que está diante de nós. A distinção dos olhares, da avaliação do que vivemos, exige certo distanciamento que nos possibilita certa distinção daquilo que já converteu o olhar, a avaliação em tirania.

diálogo aparece em Nietzsche, segundo Zittel, como forma de exposição de disposições suaves, de atenuações e de um amistoso ceticismo, de enigma e ocultamento. Afinal, por que quando muito perto o olhar fica prejudicado? Apenas distanciar-se parece já ser uma boa medida, nada violenta, mas atenua, desconfia daquilo que tão perto oculta.

Perspectivas longínquas são perspectivas que implicam a solidão. No burburinho da presença de muitos, o que fica contemplado parece borrado pelo excesso de vozes, de olhares que muitas vezes enxergam a mesma coisa e desejam que isso se generalize. A solidão exige um pensamento singular, ainda que atento ao mundo ao seu redor, exige cautela. Nietzsche destaca Heráclito como o filósofo que nos instiga a pensar considerando a solidão, o afastamento daquilo que é habitual, familiar. De fato, precisamos estar sempre em constante deslocamento "de guerra" contra nós mesmos para testar aquilo que nos orienta e nos move, e apenas isso pode ser o caminho para tornar-se o que se é. Segundo Oliveira,

[...] o familiar é o habitual; e o habitual é o mais difícil de "conhecer", isto é, de ver como problema, como alheio, distante, "fora de nós". O processo de conhecer é reconhecido por Nietzsche, portanto, como a capacidade de manutenção do problemático e do alheio e não como busca pela segurança e conforto do já habitual - isso não é conhecer, mas mero instinto de adaptação (OLIVEIRA, 2010, p. 220).

longínquo tem esse sentido, exige um afastamento do habitual, o que não significa, como diz Nietzsche, estar aborrecido com ninguém, "[...] 
mas sozinho vejo melhor meus amigos: então os vejo sob uma luz mais favorável do que me encontro ao lado deles" (NIETZSCHE, 2008, p. 230). Pensar exige distanciamento, solidão. Esse distanciamento em Nietzsche significa não se deixar levar pelo momento, ser arrastado pelas tendências, de fato a solidão é o símbolo de uma busca por si mesmo, em contraposição às demandas da massa.

Nietzsche inspira-se em Heráclito, o filósofo trágico por excelência, aquele que melhor teria captado a vida como devir. Um "homem necessário" é a representação personificada de um filósofo do devir:

O Heráclito de Nietzsche está associado à força de afirmação da vida e de celebração trágica da existência em sua multiplicidade de perspectivas. Sua veracidade está em captar essa condição e recusar a identidade do ser como dominação empobrecedora de sentido sobre a vida. Por isso sua figura é aproximada à do artista: Heráclito só descreve o mundo que existe e acha nele o mesmo prazer contemplativo com que o artista olha para a sua obra em vias de realização (OLIVEIRA, 2010, p. 226-227).

Oliveira segue nos ajudando a entender que o ato cognitivo é, então, um ato de escuta, pois os menores detalhes da vida contêm aspectos que falam da multiplicidade, das perspectivas, possuem rumores por todo lado que desejam informar sobre a vida. Será preciso distanciamento para contemplar essa intensidade de vida, para um pensar mais qualificado. Segundo Oliveira, Heráclito nos ensina e Nietzsche segue essa orientação: o pensar não é apenas intelectual, é também ação, arte, performance de uma vontade que quer estar no mundo a partir de uma vitalidade criativa. A dimensão artística tão defendida por Nietzsche implica uma ação, dar aparência, forma, àquilo que mobilizou todo nosso corpo.

Tomando esses argumentos para a pedagogia, parece que temos diante de nós um cenário desafiador: não nos deixarmos levar de imediato pelos rumores, pelas tendências, pela mobilização, inclusive dos amigos, é preciso aprender e ensinar a distância, a solidão, para concretizar em ação a dimensão artística da perspectiva longínqua. Por vezes, como nos alerta Nietzsche, é mais favorável outra luz que informa outros elementos que aqueles que vemos perto dos amigos. A necessidade de distância dos burburinhos da praça pública é um sinal de saúde. O trágico é que o "caminho próprio", por 
Perspectivas pedagógicas em Nietzsche: diálogo, agonismo e o cultivo de si

vezes, produz ofensa a quem supostamente era nosso parceiro. Começamos a ser ignorados, julgados pela distância que criamos e por ousar afastar-nos das sentenças dadas como mais adequadas sobre a vida em seu movimento. $\bigcirc$ único conselho que Nietzsche (2008, p. 230) nos oferece nessas circunstâncias: "[...] ofereça uma anistia plena por um ano a todos amigos por toda espécie de pecado".

Como podemos ver, o distanciamento não é apenas um empenho intelectual, trata-se de uma ação que tem consequências corporais, físicas, que produz efeitos, avaliações, julgamentos. Produz cenários com nossa presença e nossa ausência; e, de novo, por que a solidão?

\section{Profilaxia da solidão ${ }^{3}$}

No segundo período de produção intelectual de Nietzsche já fica evidente sua ruptura com Wagner e, consequentemente, com Schopenhaver e de como necessitou da solidão para entender inicialmente sua conexão com esses pensadores. Estar excessivamente ligado impede de pensar de forma sensata sobre os vínculos.

Avaliar um estilo de arte a distância pode nos ajudar a perceber/ pensar por que os artistas, por vezes, parecem "[...] exagerados, sem tranquilidade, menos fecundos, mais subservientes à vontade da massa, à necessidade do aplauso e da aprovação" (OLIVEIRA, 201 1, p. 134). Por esse caminho Nietzsche inicia sua crítica a Wagner.

É no exercício da solidão que consegue livrar-se de Wagner:

Solitário, então, e gravemente desconfiado de mim mesmo, tomei, não sem ira, partido contra mim e a/a favor de tudo a que me fazia mal e era duro: assim achei novamente o caminho para esse valente pessimismo que é o oposto de toda mendacidade idealista, e também, como quer me parecer, o caminho para mim - para minha tarefa... Esse oculto e soberano Algo, para o qual durante muito tempo não temos nome, até ele se revelar enfim como nossa tarefa - esse tirano em nós toma uma represália terrível contra toda tentativa que fazemos de nos esquivar ou fugir, contra toda resignação prematura, toda equiparação aos que não são nossos iguais, toda atividade, ainda que respeitável, que nos desvie do principal - e mesma toda virtude que nos protege contra a dureza da 
responsabilidade mais nossa. A cada vez a resposta é doença, quando queremos duvidar do direito à nossa tarefa, quando começamos a tornar as coisas mais fáceis para nós de algum modo. Estranho e horrível ao mesmo tempo! Os nossos alívios são o que temos de expiar mais duramente! E se quisermos depois voltar à saúde, não nos restará escolha: teremos de carregar um fardo mais pesado do que jamais carregamos antes (NIETZSCHE, 1999 p. 67).

que seria avaliar um "estilo" de pedagogia, uma didática, um currículo? Inicialmente verificar a que estamos efetivamente conectados, convencidos que seja o mais adequado dos lugares e da suposta ação educativa. Como pensadores, devemos afastar-nos dessa conexão, para outra vez pensar e talvez até rejeitar determinadas adesões. Curar-nos do burburinho da maioria. Segundo Oliveira,

[...] o barulho é símbolo da décadence porque ele é confuso, desordeiro, turbulento, cheio de efeitos que distraem do principal, conduzindo ao embaraço dos sentidos em nome de uma afirmação exagerada do intelecto. O barulho de Wagner quer conquistar espectadores a todo custo, os quais, rendidos na multidão do teatro, anulados em suas singularidades, permaneceriam os representantes máximos do fenômeno da décadence. Contra esse processo moderno constituído pela música wagneriana, Nietzsche esboça um fazer filosófico que reconheça todas as coisas como produtos humanos, demasiado humanos e recupere o valor dessas coisas para o conhecimento. Isso também passa pela valorização do silêncio como o lugar da produção original, da atividade do espírito livre, como liberdade em relação ao domínio absoluto da racionalidade. Por isso, é preciso reconhecer que o silêncio, para Nietzsche, não é apenas ausência de barulho, mas ausência de palavra, que é a causa do excesso de barulho. É a palavra racional - o logos filosófico que advém de Sócrates e Platão e que ocupa toda a filosofia moderna, vestindo a moral da antiga crença na necessária anulação dos instintos pela razão - que torna a modernidade barulhenta (OLIVEIRA, 2011 , p. 135-136).

Enfrentar a decadência: esse é o desejo de Nietzsche por meio do silêncio e da solidão. Antes do excesso das palavras, dar espaço ao corpo para entregar-se ao que não é dito - mas é vivido. Segundo Oliveira (201 1), o 
Perspectivas pedagógicas em Nietzsche: diálogo, agonismo e o cultivo de si

barulho é improdutivo porque apaga essa experiência e enche a vida moderna de insensatez e de afetação.

Para enfrentar a estupidez, necessitamos dos sentidos, olhos e ouvidos para inclusive colocar-nos no palco, em cena para avaliar a si mesmo. Experimentar a transfiguração de se reconhecer como artista de sua própria existência, sem o burburinho de tudo que nos afeta com tanta intensidade. Além da distância dos outros é preciso colocar-se à distância de si mesmo. E a referência para Nietzsche são os artistas:

Apenas os artistas, especialmente os do teatro, dotaram os homens de olhos e ouvidos para ver e ouvir, com algum prazer, o que cada um é, o que cada um experimenta e o que quer; apenas eles nos ensinaram a estimar o herói escondido em todos os seres cotidianos, e também a arte de olhar a si mesmo como herói, à distância e como que simplificado e transfigurado - a arte de se "pôr em cena" para si mesmo. Somente assim podemos lidar com alguns vis detalhes em nós! (NIETZSCHE, 2001, p. 106).

Suportar o que é vil em nós, olhar com atenção aos deslocamentos da 9 vida que acontecem entre o bem e o mal para buscar dar à vida mais dignidade. Não seremos apenas expectadores de nós mesmos, mas estar no jogo, dar ao corpo e à vida certa orientação que se ancore num constante devir criativo.

Podemos agora retomar a ideia do diálogo com a qual iniciamos esse texto, a ideia de disputa proposta por Acampora para desenhar uma ideia de cultivo de si proposta por uma outra ideia de pedagogia. Somente no silêncio e na solidão é possível dedicar-se ao cultivo, que certamente poderá avançar em direção a um diálogo onde a disputa aparece na dimensão do artístico anteriormente anunciado: inventar, criar e por vezes rejeitar o que está diante de nós. "Claustros são necessários outra vez" (MARTON, 2010). Quando, em uma das suas cartas, Nietzsche (2012. p. 347) anuncia: "Eu não suportarei por muito tempo a atmosfera das universidades [...]" ele está também avaliando e criticando esse ambiente como impeditivo para a criação. Precisaríamos de uma comunidade "claustro-artística" (OLIVEIRA, 2011 ) que cultive o silêncio como forma de afirmação e crescimento pessoal que certamente teria outras repercussões para a sociedade. 
Acampora afirma isso ao criar um vínculo entre o agon e a criação de valores. Apesar de uma necessidade de silêncio, solidão e distanciamento, as eventuais distinções individuais aproximam esse indivíduo de sua comunidade em vez de separá-lo. O cultivo de si implica disputas com o seu tempo, com a decadência, com certa barbárie que está em nós também, com o burburinho que, em alguma medida, posteriormente, retorna como oferta de outros valores, sugerindo pensar a vida em outra direção. Nesse processo do silêncio, o diálogo se estabelece como exercício de descrição de uma experiência vivida com efeitos para aqueles antes amigos, anistiados e com os quais volta-se a dialogar. Segundo Acampora:

Nietzsche busca excluir, a inveja mesquinha e a vingança como motivos para a ação na disputa. Ele pensa preservar a possibilidade de que sua resistência possa até mesmo ser considerada uma espécie de reverência, e essa condição também embasa a dimensão prática de seu trabalho. Tal engajamento acarreta as distintas realizações de sua oposição com o propósito de desafiá-las. A competição portanto ("ehren") ao criar uma ocasião para distinguir as conquistas anteriores e as valiosas qualidades do oponente. No decurso de tais disputas, Nietzsche parece crer, não podemos simplesmente derrotar ou superar aquilo a que nos opomos; em vez disso, unimo-nos ("verbinden") ao que nos opomos. [....] o agon não apenas produz indivíduos, mas também cria comunidades. Nietzsche reverencia a competição, específica e repetidamente, como um mecanismo para a produção de valores através dos quais os indivíduos e as comunidades tornam-se ligados às, não liberados das, reivindicações valorativas de terceiros (ACAMPORA, 2018 p. 2731

"Não suportarei a atmosfera da universidade por muito tempo"(NIETZSCHE, 2012, p. 174) Afinal, o que fica expresso nesse desabafo? Ele não parece encontrar espaço na universidade para o silêncio e a solidão, é preciso sempre estar em bando, em defesa de algo que já está determinado como o mais adequado. Os amigos se reúnem pelo mesmo burburinho, contudo desviar-se é dar a seriedade que merece a disputa, o agon. Segundo Acampora,

[...] o desaparecimento do agon é ruim não apenas para os indivíduos aos quais falta uma maneira de se distinguir, mas também para a comunidade como um todo. Nietzsche acredita que 
Perspectivas pedagógicas em Nietzsche: diálogo, agonismo e o cultivo de si

o agon canaliza efetivamente a agressão, coordenando-a com objetivos produtivos, e quando ele desaparece, a violência surgiu (ACAMPORA, 2018, p. 64).

direito ao afastamento da multidão, o direito à disputa enquanto está entre os seus iguais como o direito ao silêncio parecem contribuir para o cultivar a si mesmo e talvez expresse um novo desafio da pedagogia. Não seria a violência por vezes um grito de saturação do rebanho agregado diante da impossibilidade de encontrar outros espaços de formação?

Ainda precisamos de claustros, que inicialmente poderiam ser claustros para a formação de educadores, como diz Oliveira, na esteira do próprio Nietzsche, que afirma que antes de tudo é preciso educar educadores.

Esse claustro para a formação de educadores estaria em frontal desacordo com o modo de vida da sociedade moderna, pautada pela agitação, pelo trabalho volumoso e apressado, pela vulgarização e banalização dos impulsos humanos. E nas palavras de Oliveira:

Esses homens deveriam entender o conhecimento não como algo desligado da vida, mas a seu serviço... [assim, o silêncio desse claustro seria um tônico, enquanto a modernidade seria marcada pela oferta de falsos ansiolíticos e anódinos] (OLIVEIRA, 201 1, p. 140).

Oliveira, ao nos convidar a pensar uma vida simples, de forma criativa, estabelece novas conexões entre a vida ativa e contemplativa para justificar inclusive a profilaxia do silêncio. Sua recomendação parece dialogar com aquele desabafo de Nietzsche: "não sei por quanto tempo suportarei a atmosfera da universidade" e nos alerta como educadores e pesquisadores algo que reputo como fundamental:

Como 'tarefa superior' e como virtude, o silêncio aparece como uma fórmula contra a agitação da vida moderna, mas, ao mesmo tempo, como denúncia da preguiça característica do homem ativo, uma preguiça que é sintoma do medo do radical aprofundamento. O que Nietzsche evoca é um paradoxo: faz do contemplativo justamente $\mathrm{o}$ ativo e denuncia o pseudo-ativo como preguiçoso, ou seja, o homem contemplativo, porque tem uma 'tarefa', é visto precisamente como o único e mais útil para a cultura; enquanto aquele que se acredita ativo-produtivo é denunciado como um empecilho 
à vida social: 'a indolência que há no fundo da alma do homem ativo impede o ser humano de tirar água de sua própria fonte' $(H H$ 286). $\bigcirc$ homem ativo, próximo do erudito, é aquele que não sabe discutir as opiniões alheias por uma lassidão que faz com que ele mesmo não tenha nenhuma opinião. Portanto, nada pior para o conhecimento do que o tipo de atitude do homem ativo que, por preguiça de alcançar o conhecimento, prefere se esconder nas opiniões vagas e generalizadas, pairando na superfície (OLIVEIRA, 2011 , p. 146-147).

Em alguma medida, essa provocação de Oliveira nos desacomoda e exige outra perspectiva para pensar a solidão e sua profilaxia. Explica também que não está em questão a defesa de uma espécie de alienação, indiferença com sua comunidade, mas exatamente o oposto disso: por consideração às pessoas, um distanciamento é necessário para avaliar de que forma estamos orientados e se de fato essa orientação tem ainda sentido. Acampora, inclusive, aponta que quando insistimos em erradicar as disputas e apenas enfatizar a cooperação, empobrecemos a vida humana, seja em seus desdobramentos políticos, éticos, educativos e/ou culturais. Para Nietzsche, segundo ela, os esforços competitivos têm uma grande função na criação de contextos relacionais que levam outros humanos à ação criativa. Está em questão recriar o tecido social e cultural por meio de disputas inspiradas em temas que estão implicados pela vida. A perspectiva agonística em Nietzsche, segundo Acampora, implica também fazer diagnósticos. Vale lembrar que, quando da ruptura de Nietzsche com Wagner, o filósofo estabelece um diagnóstico da cultura de seu tempo. Não saber fazer diagnósticos pode produzir grandes equívocos.

Como andam nossos diagnósticos sobre a educação? Institucionalizar - agonismo (disputas) para diagnosticar implica criar espaços para uma polifonia. O que cada coisa, ou políitica pública, produziu em benefício dos humanos? As instituições precisariam (e muitas sabem disso) levantar esses dados, independentemente de uma defesa de um partido ou pessoa. Tomar as ações em andamento e apontar quais foram paralisadas, para diagnosticar nosso tempo, implica saber gerenciar, canalizar, direcionar a energia humana para produzir arranjos culturais, sociais e educativos a partir de um bom diagnóstico. As instituições, apesar de seus limites, devem ter esse papel, sustentar a boa disputa que impede a violência. Segundo Nietzsche, os gregos sabiam fazer isso, mas, em muitos momentos, somos incompetentes nesta tarefa. Por 
Perspectivas pedagógicas em Nietzsche: diálogo, agonismo e o cultivo de si

vezes, como diz Acampora seguindo Nietzsche, impedimos, ou negligenciamos, a fala de indivíduos em função do espaço que ocupam. Os arranjos criativos dependem da capacidade daqueles que participam das boas disputas, caso contrário ocorre estagnação. Assim, arranjos agonísticos declinam e decaem, o que prejudica a própria qualidade de vida social.

Nessa direção, está a nossa defesa da ideia do cultivo de si, ou seja, um cultivo, que inicia nas instituições, mas não depende delas apenas. Elas serão outras vezes necessárias para produzir arranjos criativos considerando disputas imprevisíveis que possam surgir a partir do potencial criativo dos indivíduos.

Cabe também destacar a influência de Montaigne em Nietzsche, justamente quando aquele destaca a vida contemplativa e enaltece a vida simples, tranquila, que permite ao indivíduo debruçar-se sobre si mesmo. $\mathrm{Na}$ agitação da vida produtiva, poucas possibilidades existem para elevar-se como humano. As obras de Nietzsche representam essa tentativa de olhar para si mesmo considerando os contextos que nos orientaram. A noção de fazer consigo mesmo um experimento exige afastamento, solidão, buscar um sossego fora da vida agitada e barulhenta.

Estamos orientados em excesso em uma única direção e, nesse aspecto, faz sentido falar de uma autoformação por meio do cultivo de si, lançando luz sobre o imenso empreendimento, em vários campos do humano, que insiste em nos orientar e carregar a uma única direção. Afastar-se disso faz surgir o homem soberano, que em Nietzsche significa dizer ser capaz de ampliar o olhar, adquirir a mais longínqua perspectiva sem perder os traços daquilo que também está no seu corpo e na sua história. A ação do cultivo é uma espécie de capacidade, de distinção por meio de muitas experiências, de um excesso de vida que o alcança, mas não o engole quando você conhece a medida e a necessidade da distância. Não será uma coisa a produzir a possibilidade de distinção, mas a capacidade de distanciar-se de um legado para avaliar nele o que é saudável e o que é doentio, passando pelo corpo de quem avalia.

Segundo Oliveira, o conhecimento e a ideia do cultivo de si em Nietsche não significam a conquista de um

Eu portador de um caráter fixo e imutável, mas entendido como organização provisória e instável, ou seja, como um constante 
"estado experimental". É essa, no limite, a característica do novo pensador: uma articulação entre a vida e o pensamento, fato que requer, sobretudo, a reavaliação das leis que guiam a vida e a ação humana, ou seja, uma análise crítica da própria moralidade (OLIVEIRA, 2009, p. 139).

No livro Aurora, citado por Oliveira (2008, p. 220), fica destacado no aforismo 453 uma recomendação: "[...] vivamos uma existência provisória e o melhor que podemos fazer ao nosso gosto e nosso talento é 'fundar pequenos estados de experimentação'". Somos experiência e só por meio delas poderemos formular novas leis da vida e da ação. Assim, não existe um "eu" capaz de estar acima de toda experiência para, então, regenerar a cultura. Estamos imersos nos terrenos da moralidade, da política, somos e fazemos experiências nesses terrenos, que podem fundar os estados de experimentação para avaliar, outra vez, os gostos e estilos que estão em questão em cada tempo e período e quais impactos têm sobre nós. Existe um contágio da multidão, como nos diz Montaigne, ele desfaz o estado de experimentação para solicitar adesão. O próprio filósofo recomenda que é preciso sequestrar-se para recuperar-se da multidão. E preservando-se, nos preparamos para o enfrentamento da multidão, como um processo de retomada de possibilidades mais criativas de convívio, onde os apelos e tutelas foram expurgados.

Recuperar a saúde significa ser capaz de voltar para a multidão sem ser levado por ela. Assim, segundo Nietzsche, na descrição de Oliveira:

A solidão está associada, portanto, a "longos e perigosos exercícios de autodomínio" que levam da doença à saúde e possibilitam a grande suspeita no que diz respeito aos valores instaurados. Para Nietzsche, na esteira de Montaigne, esse exercício torna a solidão não uma consternada aflição ou um mero desalento pessoal, mas, acima de tudo, uma prática revigoradora, porque rejuvenesce e refina o espírito que passa a repugnar com mais ênfase a grosseira fruição dos "homens cultos" e a "escutar com mais malícia" - barulho da feira e o "grito teatral da paixão" que embebeda a arte: imagens da vida gregária usadas por Nietzsche, a erudição, o mercado e o teatro, demonstram o que a filosofia e a arte têm de obsoleto e remoto. Por outro lado, é na solidão que o homem nobre se aprofunda e se torna capaz de vencer a doença, como manifestação da sua grande saúde conquistada na afirmação de si mesmo. Trata-se desta capacidade de autorregeneração, própria das fontes de águas abertas à beira da estrada, que recebem todos 
Perspectivas pedagógicas em Nietzsche: diálogo, agonismo e o cultivo de si

os peregrinos sedentos que muitas vezes the turvam a limpidez com lixos e sujeiras as mais variadas: "Mas nós faremos como sempre fizemos: levamos o que nos lançam para a nossa profundidade pois nós somos" (OLIVEIRA, 2009, p. 140-141).

diálogo em Nietzsche, e sua perspectiva pedagógica, foi discutida neste texto considerando as reflexões de Zittel, Acampora e Oliveira. Eles próprios não dialogaram, foi nosso o esforço reuni-los para operar pedagogicamente com Nietzsche. Está em questão uma defesa de que Nietzsche nos ensina a arte do diálogo, uma ideia de conversação sem violência, mas com disputas que permitem fazer aparecer a distinção entre os humanos. Tal distinção não é um empreendimento desvinculado de sua comunidade. Pelo contrário: em alguns momentos, é preciso afastar-se da multidão, do burburinho, para de novo entender o que significa pensar sem ser empurrado para determinada posição. Nesse esforço, a solidão e o silêncio são ingredientes necessários para sofisticar o diálogo com a multidão. Esse encontro jamais desejará buscar adesão, contudo, sugere que vivamos uma existência provisória cultivada por nossas experiências nos mais diferentes terrenos sociais para fundar efetivos estados de experimentação e, eventualmente, tomarmos sempre outras e novas orientações para pensar a vida e nossa ação.

A solidão, o diálogo, a disputa nos purificam em determinado sentido, deixam aparecer também a sujeira de cada um para acessar o vigor de um mundo para além do bem e do mal. Será preciso superar a sujeira de nosso tempo, de nossa pedagogia, de nossas convicções, para dar vazão a um espírito que precisa ser livre para deixar de ser enfermo e voltar a ter saúde. $\bigcirc$ grande combate é contra a enfermidade de nosso corpo, que nos imobiliza e nos faz rebanhos. Para evitar isso, precisamos dar a nós mesmos essa condição de estados de experimentação, distanciar-nos para escutar nosso tempo e recuperar em nós uma alegria que insistem em nos roubar. A perspectiva pedagógica em Nietzsche é produzir esse estado de experimentação naqueles que, nas instituições, parecem cansados de ser conduzidos e estão ansiosos para pensar. 


\section{Considerações finais}

O texto pretendeu destacar o lugar do diálogo e do agonismo na obra de Nietzsche para solicitar atenção à ideia do cultivo de si, muitas vezes desprezada em nossas ações educacionais. Em alguma medida, somos sempre conduzidos por motivações coletivas, sem dúvida, muito próprias, dependendo de suas articulações e motivações. Contudo, elas não contemplam todas as possibilidades humanas.

Tanto a disputa quanto o diálogo nas práticas educativas são procedimentos de enfrentamento da violência, produzindo valores, padrões de medida e sentidos para a convivência humana. Nesse contexto, criar valores e medidas é, em alguma medida, também uma expressão de nossa singularidade, não para viver no isolamento, mas, justamente, para voltar ao coletivo sem ser seduzido por determinadas orientações dadas como indiscutíveis.

A ideia do cultivo de si, desenvolvida por Nietzsche, inaugura outra pedagogia, que nos coloca no lugar de quem é convidado a evitar a ossificação de uma perspectiva na forma de tirania e ativar em cada o seu processo de individualização, que, em alguma medida, é um antídoto para evitar ser tutelado.

texto desejou destacar a dimensão do diálogo como forma filosófica em Nietzsche, visando a apreender a dimensão pedagógica presente na obra do filósofo. $\bigcirc$ diálogo que também respeita a disputa, reconhece a diversidade humana que, uma vez vivenciada, nos conduzirá a um pensar e agir mais livremente, contribuindo para dar à educação um tanto de beleza.

É o próprio Nietzsche que recomenda em seus escritos que a liberdade está conectada com pequenas ações divergentes que se mostram necessárias para afirmar a possibilidade de inventar e criar outras práticas, em nosso caso, outras experiências pedagógicas. As pequenas ações divergentes são oriundas da singularidade, precisam ser cultivadas para terem visibilidade. Sujeitos, capazes de criar pequenas ações divergentes, não buscam o caos, mas, por vezes, desejam expressar a incompletude de argumentos e práticas dadas como adequadas e democráticas. A noção de vontade de potência em Nietzsche tem relação com o tornar-se o que se é, com a necessidade de superação de si, deslocar-se no tempo por meio de ideias e ações, correr riscos. $\bigcirc$ cultivo de si implica querer ser outro, querer ser mais forte, desejar identificar 
Perspectivas pedagógicas em Nietzsche: diálogo, agonismo e o cultivo de si

os limites de nossa existência. Não estariam nessas expectativas as grandes questões da educação, da formação humana?

Em que medida o educador pode assumir esta tarefa, ou melhor, fazer com que o diálogo e a disputa possam garantir a expansão das forças em exercício nas instituições para verificar que, nesse campo de instabilidades, lutas e práticas o que deve ser banido é a própria permanência e até mesmo a identidade para deixar aparecer a diferença?

Façamos este exercício docente com sofisticação, de fato, uma cortesia com aqueles que nos esperam nas instituições e que, talvez, estejam interessados em escutar e ver seu tempo com novas ferramentas e procedimentos.

\section{Notas}

1 Prof. Dr. Claus Zittel, professor de literatura e filosofia alemã nas Universidades de Stuttgart e Frankfurt am Main, vice-diretor do Centro de Pesquisa de Estudos de Texto de Stuttgart. O texto referência utilizado nesse artigo é uma tradução (parcial/2016) realizada pelo professor Jorge Luiz Viesenteiner (UFES), ainda não publicada, contudo, autorizada para divulgação.

2 Christa Davis Acampora é professora de Filosofia na Universidade de Emory, em Atlanta, Georgia (EUA).

3 A expressão "profilaxia da solidão" é uma inspiração a partir do texto de Oliveira (201 1).

4 Presente trabalho foi realizado com apoio do CNPq, Conselho Nacional de Desenvolvimento Científico e Tecnológico - Brasil.

\section{Referências}

ACAMPORA, Christa Davis. As disputas de Nietzsche. Tradução Peterson Roberto da Silva. Florianópolis: Editora da UFSC, 2018.

MARTON, Scarlett. Claustros vão se fazer outra vez necessários. In: Nietzsche, seus leitores e suas leituras. São Paulo: Barcarolla, 2010.

NIETZSCHE, Friedrich. Além do bem e do mal. Prelúdio a uma filosofia do futuro. Tradução, notas e posfácio Paulo César de Souza. São Paulo: Companhia das Letras, 1992.

NIETZSCHE, Friedrich. O caso Wagner: um problema para músicos/Nietzsche contra Wagner: dossiê de um psicólogo. Tradução e posfácio Paulo Cesar de Souza. São Paulo: Companhia das Letras, 1999. 
NIETZSCHE, Friedrich. Humano, demasiado humano. Tradução, notas e posfácio Paulo César de Souza. São Paulo: Companhia das Letras, 2000.

NIETZSCHE, Friedrich. A gaia ciência. Tradução, notas e posfácio Paulo César de Souza. São Paulo: Companhia das Letras, 2001.

NIETZSCHE, Friedrich. Aurora: reflexões sobre os preconceitos morais. Tradução, notas e posfácio Paulo César de Souza. São Paulo: Companhia das Letras, 2004.

NIETZSCHE, Friedrich. Escritos sobre educação. Tradução Noéli Correia de Melo Sobrinho. Rio de Janeiro: Editora Puc-Rio/ São Paulo: Loyola, 2004.

NIETZSCHE, Friedrich. Crepúsculo dos ídolos ou como se filosofa com o martelo. Tradução Paulo César de Souza. São Paulo: Companhia das Letras, 2006.

NIETZSCHE, Friedrich. Assim falava Zaratustra. Um livro para todos e para ninguém. Tradução Mário Ferreira dos Santos. Petrópolis: Vozes, 2007.

NIETZSCHE, Friedrich. Ecce homo: como alguém se torna o que é. Tradução Paulo César de Souza São Paulo: Companhia das Letras, 2008.

NIETZSCHE, Friedrich. Genealogia da moral. Tradução Mário Ferreira dos Santos. Petrópolis: Vozes, 2009.

NIETZSCHE, Friedrich. Correspondência II - abril 1869 a diciembre de 1874. Tradução e notas Andrés Rubio. Madrid: Editorial Trotta, 2012. (Organização Luis Enrique de Santiago Guervós).

OLIVEIRA, Jelson. Apontamentos sobre a influência de Montaigne sobre Nietzsche nos escritos do segundo período. Cadernos de Ética e Filosofia Políitica, São Paulo, v. 14, n. 1, p. 123-145, 2009.

OLIVEIRA, Jelson. Nietzsche e o Heráclito que ri: solidão, alegria trágica e devir inocente. Veritas, Porto Alegre, v. 55, n. 3, p. 217-235, set./dez. 2010.

OLIVEIRA, Jelson. A profilaxia do silêncio. ethic@, Florianópolis, v. 10, n. 1, p. 133-155, jun. 2011.

ZITTEL, Claus. Der dialog als philosophische Form bei Nietzsche. In: Nietzsche-Studien. Internationales Jahrbuch für die Nietzsche-Forschung, Bd. 45. 2016. (Artigo apresentado em evento em Florianópolis-SC e traduzido por Jorge Luiz Viesenteiner). 
Artigo

Perspectivas pedagógicas em Nietzsche: diálogo, agonismo e o cultivo de si

Profa. Dra. Lúcia Schneider Hardt

Universidade Federal de Santa Catarina (Brasil)

Departamento de Estudos Especializados em Educação

Líder do Grupo de Pesquisa GRAFIA

Coordenadora do Sub: Grupo Bio-Grafia/Nietzsche

Bolsista em Produtividade em Pesquisa do CNPq (PQ-2)

ORCID: http:// orcid.org/0000-0002-4939-0156

E-mail: luciashardł@gmail.com

Recebido 17 out. 2019

Aceito 2 dez. 2019 